\title{
(2) OPEN ACCESS \\ British Society of Gastroenterology (BSG)-led multisociety consensus care bundle for the early clinical management of acute upper gastrointestinal bleeding
}

\author{
Keith Siau (1) , ${ }^{1,2,3}$ Sarah Hearnshaw, ${ }^{4}$ Adrian J Stanley, ${ }^{5}$ Lise Estcourt, ${ }^{6}$ \\ Ashraf Rasheed, ${ }^{7,8}$ Andrew Walden, ${ }^{9,10}$ Mo Thoufeeq, ${ }^{11}$ Mhairi Donnelly, ${ }^{5}$ \\ Russell Drummond, ${ }^{5}$ Andrew M Veitch, ${ }^{12}$ Sauid Ishaq, ${ }^{3,13}$ \\ Allan John Morris ${ }^{5,14}$
}

For numbered affiliations see end of article.

Correspondence to Dr Allan John Morris, Glasgow Royal Infirmary, Glasgow G4 OSF, UK; john.morris@ggc.scot.nhs.uk

British Society of Gastroenterology Conference 2019

Published Online First 27 March 2020
Check for updates

(C) Author(s) (or their employer(s)) 2020. Re-use permitted under CC BY-NC. No commercial reuse. See rights and permissions. Published by BMJ.

To cite: Siau K, Hearnshaw S, Stanley AJ, et al. Frontline Gastroenterology

2020;11:311-323.

\section{ABSTRACT}

Medical care bundles improve standards of care and patient outcomes. Acute upper gastrointestinal bleeding (AUGIB) is a common medical emergency which has been consistently associated with suboptimal care. We aimed to develop a multisociety care bundle centred on the early management of AUGIB.

Commissioned by the British Society of Gastroenterology (BSG), a UK multisociety task force was assembled to produce an evidencebased and consensus-based care bundle detailing key interventions to be performed within 24 hours of presentation with AUGIB. A modified Delphi process was conducted with stakeholder representation from BSG, Association of Upper Gastrointestinal Surgeons, Society for Acute Medicine and the National Blood Transfusion Service of the UK. A formal literature search was conducted and international AUGIB guidelines reviewed. Evidence was appraised using the Grading of Recommendations, Assessment, Development and Evaluation tool and statements were formulated and subjected to anonymous electronic voting to achieve consensus. Accepted statements were eligible for incorporation into the final bundle after a separate round of voting. The final version of the care bundle was reviewed by the BSG Clinical Services and Standards Committee and approved by all stakeholder groups.

Consensus was reached on 19 statements; these culminated in 14 corresponding care bundle items, contained within 6 management domains: Recognition, Resuscitation, Risk assessment, Rx (Treatment), Refer and Review.

A multisociety care bundle for AUGIB has been developed to facilitate timely delivery of evidence-based interventions and drive quality improvement and patient outcomes in AUGIB.

\section{INTRODUCTION}

Acute upper gastrointestinal bleeding (AUGIB) is a common medical emergency in the UK with an estimated incidence of 134 per 100000 population, ${ }^{1}$ roughly equating to one presentation every $6 \mathrm{~min}$. Mortality following AUGIB over the last two decades has remained high at approximately $10 \%,{ }^{2}$ with several UK-wide audits revealing poor standards of care. ${ }^{23}$ Multiple guidelines have been developed in an attempt to define quality standards in AUGIB and improve patient outcomes. ${ }^{4-6}$ These unanimously acknowledge the importance of timely management within the first 24 hours as early resuscitation and endoscopy correlate with improved outcomes. Despite this, the 2015 UK National Confidential Enquiry into Patient Outcome and Death (NCEPOD) audit highlighted ongoing variations in practice and suboptimal care in patients with AUGIB. ${ }^{7}$ As such, strategic initiatives remain necessary to address these long-standing deficiencies and drive sustained improvement.

The care bundle approach to medical care has become increasingly popular in recent years. ${ }^{8}$ Care bundles comprise a pragmatic series of evidence-based interventions, which when performed together, lead to a better outcome than if performed individually. ${ }^{8}$ Developed in 2004, the Sepsis Six bundle has achieved UK-wide implementation and has been shown to reduce 
mortality. ${ }^{10}$ The 2014 British Society of Gastroenterology (BSG) and British Association for the Study of the Liver (BASL) care bundle for decompensated chronic liver disease was released in response to NCEPOD recommendations, ${ }^{11}$ and has improved adherence to standards of care and reduced length of stay (LOS). ${ }^{12}$ In endoscopy, implementation of the Quality Improvement in Colonoscopy bundle led to improvements in adenoma detection rates. ${ }^{13}$ Thus, care bundles can facilitate the timely delivery of minimum standards of care, which can ultimately improve patient outcomes. ${ }^{8}{ }^{14} \mathrm{We}$ propose that a consensus evidence-based care bundle specific for AUGIB and deliverable within the first 24 hours of presentation could improve the care and clinical outcomes of patients with AUGIB. We therefore aimed to produce an evidence and consensus-based care bundle for the first 24 hours from presentation in patients with suspected AUGIB. The bundle is intended to be used by all healthcare professionals involved in the initial management of patients with AUGIB. Detailed endoscopic management is beyond the scope of wardbased care and is therefore not included.

\section{METHODS}

The UK AUGIB care bundle was developed as part of the BSG Endoscopy Quality Improvement Programme (EQIP). ${ }^{15}$ The steering committee comprised a multidisciplinary group of experts from BSG, Association of Upper Gastrointestinal Surgeons, National Health Service (NHS) Blood and Transplant, Society for Acute Medicine, with trainee and patient representation. The consensus process involved a modified Delphi method. Members were assigned to working groups corresponding to different sections of the care bundle. Sequentially, these comprised: Recognition, Resuscitation, Risk Stratification, Rx (Treatment), Refer (referral for endoscopy) and Review (postendoscopic management). Each working group framed questions relevant to pre-endoscopic and postendoscopic interventions using the Patient, Intervention, Comparator, Outcome (PICO) method, and performed literature searches on PUBMED, EMBASE, and Cochrane Database of Systematic Reviews in June 2018. International AUGIB guidelines were also reviewed. For guidelines produced before 2013, searches were updated using original search strategies to identify more recent publications. Based on the PICO tables, statements relevant to early AUGIB management were formulated and the level of evidence for each statement appraised in accordance with Grading of Recommendations, Assessment, Development and Evaluations methodology. ${ }^{16}$ Each statement was paired with a care bundle item. The process was peer-reviewed through multiple teleconferences. Once working groups had formulated initial evidence-based statements, a face-to-face meeting with anonymised electronic voting was arranged to evaluate consensus with statements and care bundle items. The level of agreement was measured on a five-point Likert
Scale (A: strongly agree, B: agree, C: neither agree nor disagree, D: disagree, E: strongly disagree) following evidence appraisal for each statement. The number voting for each level was recorded and presented with each statement. A threshold of $80 \%$ agreement (rated A or B) was defined a priori to accept a statement; statement revisions were permitted if they did not meet this threshold. Each statement underwent up to three rounds of voting. Accepted statements were considered for incorporation into the final bundle after a separate voting process. A level of recommendation (weak/ strong) was assigned to each statement. Although it is standard practice to align recommendations with the level of evidence, statements could receive discordant recommendations (eg, strong recommendation for low-quality evidence) if the perceived benefit in clinical practice outweighed the paucity of available evidence. The final version of the care bundle was reviewed and approved by stakeholder groups, including the BSG Clinical Services and Standards Committee, prior to submission for publication. Focused top-up searches were also performed in October 2019 to ensure that the evidence was updated prior to publication.

\section{CONSENSUS STATEMENTS}

Following evidence review, the modified Delphi process reached consensus on 19 recommendations (table 1). These culminated into 14 corresponding care bundle items (figure 1), enveloped within six management domains: Recognition, Resuscitation, Risk stratification, Rx (Treatment), Referral and Review (postendoscopy care).

\section{RECOGNITION}

We recommend that patients with haematemesis, melaena or coffee ground vomiting (CGV) in the absence of an alternate diagnosis (eg, bowel obstruction) trigger the AUGIB bundle

Level of evidence: Low

Level of recommendation: Strong

Agreement: 100\%

Bundle recommendation: Trigger bundle if haematemesis, melaena or CGV (100\% agreement)

Haematemesis and melaena are recognised symptoms of AUGIB. CGV refers to emesis that contains dark altered blood not due to any other cause such as bowel obstruction or sepsis. The appropriateness of including CGV as a trigger for the AUGIB bundle was evaluated. A recent study $(n=3012)$ prospectively compared outcomes following presentation with CGV compared with overt haematemesis and/or melaena. ${ }^{17}$ Clinical severity measured using risk stratification tools were all significantly lower in the isolated haematemesis group than in the CGV group, as CGV was associated with older patients with comorbidity. Although haematemesis was independently associated with higher rates of haemostatic intervention and rebleeding than CGV, there were no significant differences in the 


\begin{tabular}{|c|c|c|}
\hline Recommendation statement & $\begin{array}{l}\text { Level of } \\
\text { evidence }\end{array}$ & $\begin{array}{l}\text { Level of } \\
\text { recommendation }\end{array}$ \\
\hline $\begin{array}{l}\text { We recommend that patients with haematemesis, melaena, or coffee ground vomiting in the absence of an } \\
\text { alternate diagnosis (eg, bowel obstruction) trigger the acute upper gastrointestinal bleeding (AUGIB) bundle. }\end{array}$ & Low & Strong \\
\hline $\begin{array}{l}\text { We recommend that patients with suspected AUGIB should have urgent observations performed using a } \\
\text { validated early warning score such as the National Early Warning Score (NEWS). }\end{array}$ & Low & Strong \\
\hline $\begin{array}{l}\text { We recommend all patients with AUGIB be commenced on intravenous fluids. We recommend in } \\
\text { haemodynamically unstable patients a crystalloid solution as a bolus of } 500 \mathrm{~mL} \text { in less than } 15 \mathrm{~min} \text {. }\end{array}$ & Very low & Strong \\
\hline $\begin{array}{l}\text { We recommend that red blood cell transfusion should follow a restrictive protocol (trigger: } \mathrm{Hb}<70 \mathrm{~g} / \mathrm{L} \text {; target: } \\
70-100 \mathrm{~g} / \mathrm{L} \text { ). A higher trigger should be considered in patients with ischaemic heart disease or haemodynamic } \\
\text { instability. }\end{array}$ & High & Strong \\
\hline $\begin{array}{l}\text { We recommend that patients with AUGIB with ongoing haemodynamic instability are referred for critical care } \\
\text { review. }\end{array}$ & Very low & Strong \\
\hline $\begin{array}{l}\text { We suggest that platelets should be given in active acute upper Gl bleeding with a platelet count } \leq 50 \times 10^{9} / \mathrm{L} \text {, as } \\
\text { per major haemorrhage protocols. }\end{array}$ & Very low & Weak \\
\hline We recommend the Glasgow-Blatchford Score (GBS) is calculated at presentation with AUGIB. & Moderate & Strong \\
\hline We recommend that patients with $\mathrm{GBS} \leq 1$ at presentation are considered for outpatient management. & Moderate & Strong \\
\hline $\begin{array}{l}\text { We recommend intravenous terlipressin is given to all patients with suspected cirrhosis/variceal bleeding. } \\
\text { However, caution should be exercised in patients with ischaemic heart disease or peripheral vascular disease. }\end{array}$ & High & Strong \\
\hline $\begin{array}{l}\text { We recommend giving intravenous antibiotics as per local protocol to patients with suspected cirrhosis/variceal } \\
\text { bleeding. }\end{array}$ & High & Strong \\
\hline We recommend continuing aspirin at presentation. & Moderate & Strong \\
\hline $\begin{array}{l}\text { We recommend interrupting P2Y12 inhibitors until haemostasis is achieved unless the patient has coronary } \\
\text { artery stents, in which case, a decision should be undertaken after discussion with a cardiologist. }\end{array}$ & Moderate & Strong \\
\hline We recommend interrupting warfarin therapy at presentation. & Low & Strong \\
\hline We recommend interrupting direct oral anticoagulant therapy at presentation. & Low & Strong \\
\hline $\begin{array}{l}\text { We recommend endoscopy is offered to patients admitted with suspected AUGIB within } 24 \text { hours of } \\
\text { presentation. Patients with ongoing haemodynamic instability will require more urgent endoscopy after } \\
\text { resuscitation. }\end{array}$ & Low & Strong \\
\hline We suggest that the endoscopy report should be reviewed by the ward team. & Very low & Strong \\
\hline $\begin{array}{l}\text { We suggest that all patients with varices or those requiring endoscopic therapy are referred to a specialist } \\
\text { gastroenterology service. }\end{array}$ & Low & Strong \\
\hline $\begin{array}{l}\text { We recommend patients with bleeding from ulcers with high-risk stigmata at endoscopy receive high-dose } \\
\text { intravenous proton pump inhibitor (PPI) therapy; high-dose oral PPIs may be considered as an alternative. }\end{array}$ & High & Strong \\
\hline $\begin{array}{l}\text { We recommend patients with AUGIB in whom antithrombotic therapy is interrupted have a clear plan for } \\
\text { resumption. }\end{array}$ & Low & Strong \\
\hline
\end{tabular}

composite outcome of transfusion requirement, endoscopic intervention or death between presenting symptoms. Hence CGV should be considered a presenting feature of AUGIB.

\section{RESUSCITATION}

\section{We recommend that, on admission or presentation with suspected AUGIB, urgent observations be performed using a validated early warning score such as the National Early Warning Score (NEWS)}

Level of evidence: Low

Level of recommendation: Strong

Agreement: $80 \%$

Bundle recommendation: Perform NEWS (100\% agreement)

All patients with AUGIB require urgent assessment of their haemodynamic status followed by reassessment at regular intervals. Early warning scores serve as a composite indicator of a patient's physiological status and are used to identify deteriorating patients and trigger medical interventions. These can be used to determine bleeding severity, screen for rebleeding in stable patients, guide fluid resuscitation and determine intervention, for example, frequency of observations, escalation of care, and so on. The role of early warning scores in AUGIB has been presented in a single-centre study $(\mathrm{n}=202)$ which compared a Modified Early Warning Score (MEWS) based on five admission parameters (systolic blood pressure, heart rate, respiratory rate, temperature and consciousness level) with the Glasgow-Blatchford Score (GBS) and the Pre-endoscopic Rockall (PER) Score in predicting outcomes. ${ }^{18}$ There was significant correlation between the admission MEWS and the outcomes of hospital admission and death $(\mathrm{p}<0.001)$. MEWS $>2$ was superior for predicting mortality (area under the receiver operating characteristics curve (AUROC) 0.772, $\mathrm{p}<0.001$ ) compared with GBS >13 (AUROC 0.679, $\mathrm{p}=0.022$ ) and PER Score (AUROC 0.767, $\mathrm{p}<0.001$ ). 


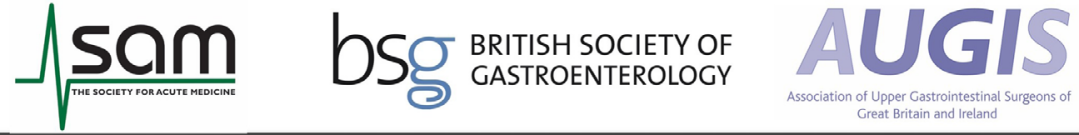 \\ UK Acute Upper GI Bleeding Bundle (to be performed within 24h) \\ Patient Details / Label \\ Name: \\ D.O.B.: \\ Hospital No.: \\ Date:}

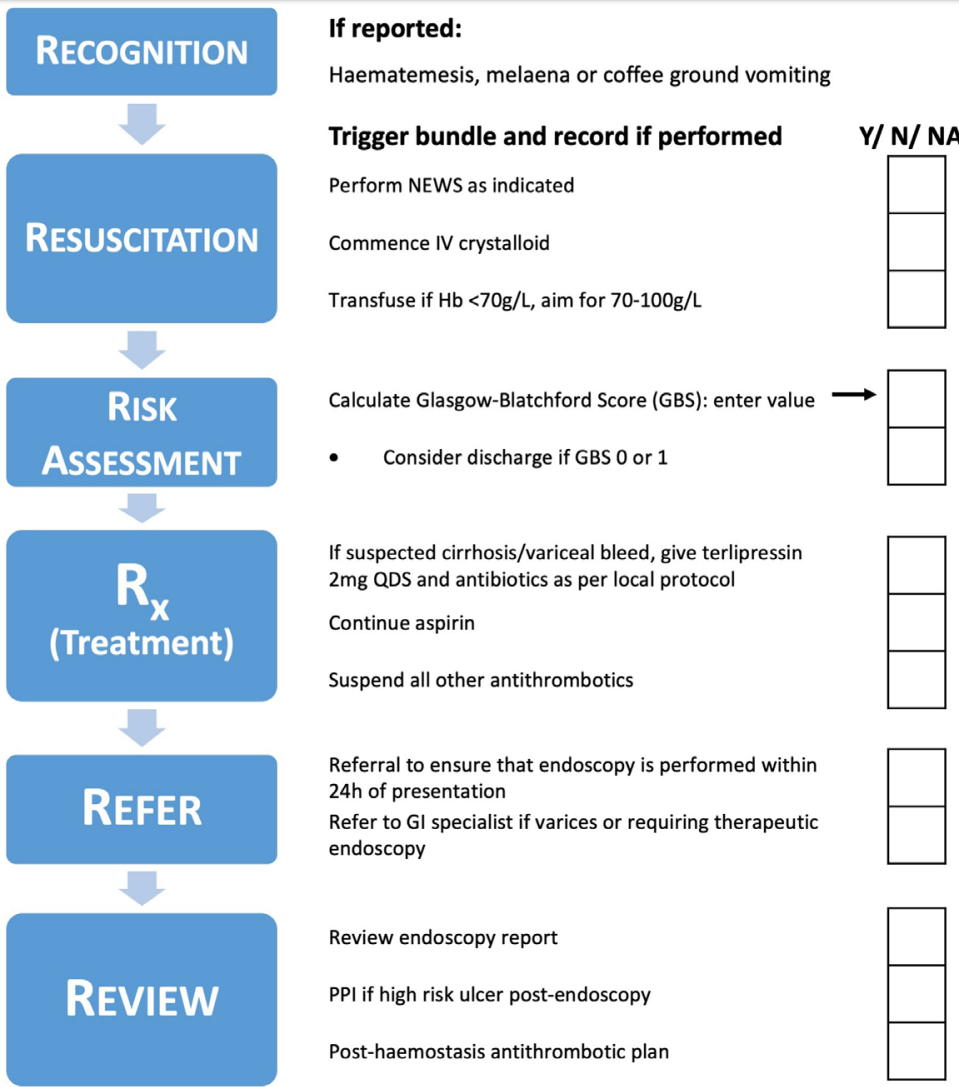

\section{Haemodynamic instability? Think Major Haemorrhage Protocol +/-} critical care review

Figure 1 Summary of the BSG-led acute upper gastrointestinal bleeding care bundle. NEWS, National Early Warning Score; PPI, proton pump inhibitor

MEWS $>1$ was also predictive of transfusion requirements (AUROC 0.584, $\mathrm{p}=0.047$ ), but not rebleeding (AUROC $0.617, \mathrm{p}=0.064$ ) or endoscopic therapy (AUROC 0.508, $\mathrm{p}=0.862$ ). ${ }^{18}$

NEWS has received endorsement by the Royal College of Physicians and NHS England for use in all acutely ill patients. ${ }^{19}$ To align with these recommendations, we recommend the use of NEWS, or a similarly validated early warning score, at presentation with suspected AUGIB.

We recommend all patients with AUGIB be commenced on intravenous fluids. We recommend a crystalloid solution with a bolus of $500 \mathrm{~mL}$ over less than $15 \mathrm{~min}$, in haemodynamically unstable patients

Level of evidence: Very low

Level of recommendation: Strong
Agreement: 100\%

Bundle recommendation: Commence intravenous crystalloid ( $80 \%$ agreement)

Haemodynamic instability is defined by the National Institute for Health and Care Excellence (NICE) as active bleeding where blood pressure or pulse cannot be normalised or where rapid intravenous fluids are required to maintain haemodynamic stability. ${ }^{5}$ There are no randomised controlled trials (RCTs) comparing different fluid regimens in AUGIB.

Two small non-randomised studies assessed the volume of fluid administration in AUGIB. The first $(n=51)$ included patients with variceal bleeding and haemorrhagic shock and compared dopamine with restricted fluid versus liberal fluids only. ${ }^{20}$ There were no significant 
differences in mortality or LOS, but evidence of reductions in acute respiratory distress syndrome, multiorgan failure and sepsis in favour of the dopamine group. The second associated early intensive resuscitation in AUGIB with reduced rates of mortality and myocardial infarction. ${ }^{21}$ However, the intervention involved a physician providing dedicated one-to-one input (no other clinical duties other than caring for the patient with AUGIB) and therefore cannot be proposed as standard care in routine clinical practice.

The NICE guideline on intravenous fluids recommends fluid resuscitation with $500 \mathrm{~mL}$ crystalloid over less than $15 \mathrm{~min}^{22}$ This is based on a Cochrane review comparing crystalloids with colloids in critically ill patients. ${ }^{23}$ The European Society of Gastrointestinal Endoscopy (ESGE) AUGIB guidelines ${ }^{6}$ contain a recommendation on prescribing intravenous fluids based on this Cochrane review ${ }^{23}$ and a high-quality single-centre RCT. $^{24}$ ESGE guidelines recommend prompt intravascular volume replacement using crystalloid fluids if haemodynamic instability exists. ${ }^{6}$ Fluid administration has not featured in other AUGIB guidelines.

Regardless of haemodynamic status at presentation, we recommend that all patients with AUGIB should be commenced on intravenous fluid replacement and that monitoring of NEWS and clinical review are required to determine the infusion rate.

\section{We recommend that red blood cell (RBC) transfusion should follow a restrictive protocol (trigger: $\mathrm{Hb}$ $<70 \mathrm{~g} / \mathrm{L}$; target: $70-100 \mathrm{~g} / \mathrm{L}$ ). A higher trigger should be considered in patients with ischaemic heart disease or haemodynamic instability}

Level of evidence: High

Level of recommendation: Strong

Agreement: 100\%

Bundle recommendation: Transfuse if $\mathrm{Hb}<70 \mathrm{~g} / \mathrm{L}$ with a target of $70-100 \mathrm{~g} / \mathrm{L}$ (100\% agreement)

Five RCTs have assessed the use of different transfusion thresholds; ${ }^{25-29}$ these were summarised in a systematic review $(n=1965) \cdot{ }^{30}$ Ninety-three per cent of patients were derived from two RCTs which included both variceal and non-variceal AUGIB. ${ }^{26}{ }^{27}$ Only one RCT included participants regardless of age, comorbidity or history of ischaemic heart disease. ${ }^{26}$ The study by Villanueva et al $(n=889)$ was a single-centre Spanish RCT that compared a threshold of $70 \mathrm{~g} / \mathrm{L}$ with $90 \mathrm{~g} / \mathrm{L} .{ }^{27}$ All participants received endoscopy within 6 hours. The study by Jairath et al was a multicentre UK cluster randomised RCT that compared a threshold of $80 \mathrm{~g} / \mathrm{L}$ with $100 \mathrm{~g} / \mathrm{L} .{ }^{26}$ In the meta-analysis, a restrictive transfusion strategy was associated with a reduction in all-cause mortality at 30 days (26 fewer deaths per 1000; 95\% CI 2 to 42); rebleeding (57 fewer rebleeding episodes per 1000; 95\% CI 21 to 81), transfusion requirement (mean difference $-1.73 \mathrm{RBC}$ units; 95\% CI -2.36 to $-1.11)$; number of people who required a transfusion (276 fewer per 1000; 95\% CI 164 to 361) and LOS (mean difference -1.9 days; $95 \%$ CI 3.34 to 0.46 ). ${ }^{30}$ No difference was found between the variceal and nonvariceal subgroups. No RCTs included participants with exsanguinating haemorrhage, where haemoglobin may not be an accurate measure of blood loss. ${ }^{31}$ In such cases, patients should be managed in line with major haemorrhage guidelines. ${ }^{32}$ Rates of RBC transfusion should be guided by the speed of blood loss and the level of haemodynamic compromise. ${ }^{32}$

We recommend that patients with AUGIB with ongoing haemodynamic instability are referred for critical care review

Level of evidence: Very low

Level of recommendation: Strong

Agreement: 100\%

Bundle recommendation: If haemodynamically unstable, consider activating major haemorrhage protocol and arranging critical care review (added as standalone statement in bundle)

The study by Baradarian et al associated intensive monitoring and management of haemodynamic instability with improved outcomes. ${ }^{21}$ Patients with AUGIB may also suffer complications caused by nonhypovolaemic causes of shock, for example, sepsis in patients with cirrhosis. Haemodynamic instability per se should not be the sole determinant for critical care admission. ${ }^{33}$ In cases of ongoing haemodynamic instability despite adequate resuscitative efforts, activation of the major haemorrhage protocol should be considered in addition to early referral to a critical care specialist in order to optimise circulatory management. ${ }^{32} 34$

\section{We suggest that platelets should be given in active AUGIB with a platelet count $\leq 50 \times 10^{9} / \mathrm{L}$, as per major haemorrhage protocols}

Level of evidence: Very low

Level of recommendation: Weak

Agreement: 90\%

Bundle recommendation: Keep platelet count $>50$ (included as part of major haemorrhage protocol, therefore no separate statement required)

No RCTs have assessed the role of platelet transfusions or platelet transfusion thresholds. ${ }^{35}$ There is little evidence for the effectiveness of platelet transfusions or the optimal dose when a patient with a thrombocytopenia is actively bleeding. ${ }^{36}$ In patients without pre-existing thrombocytopenia, acquired thrombocytopenia may be a late event in major haemorrhage, occurring after blood loss of at least 1.5 total blood volumes. ${ }^{32}$ Guidance for a platelet transfusion threshold in major bleeding is based on expert opinion only, and is consistently recommended by $\mathrm{NICE}^{5} 37$ and the British Society for Haematology. ${ }^{32}$ Due to the limited evidence and its coverage within the major haemorrhage protocol, a separate bundle statement for thrombocytopaenia correction was not included. 


\section{RISK STRATIFICATION}

We recommend GBS is calculated at presentation with AUGIB

Level of evidence: Moderate

Level of recommendation: Strong

Agreement: 100\%

Bundle recommendation: Calculate GBS (100\% agreement)

We recommend that patients with GBS $\leq 1$ at presentation are considered for outpatient management

Level of evidence: Moderate

Level of recommendation: Strong

Agreement: 100\% Agreement

Bundle recommendation: Consider discharge if GBS 0 or 1 (100\% agreement)

Several comparative studies have assessed preendoscopy and postendoscopy risk scores in AUGIB. ${ }^{38-49}$ These studies confirm GBS is the best at predicting the clinically important composite end point of need for hospital-based intervention (transfusion, endoscopic therapy, interventional radiology, surgery) or death, with high sensitivity at $98.6 \%$. $^{39}$ The clinical utility of existing risk scores to identify patients at high risk of poor outcomes appear limited. The AIMS65 and PER Scores appear best at predicting death after AUGIB, ${ }^{4142444650}$ and use of the full Rockall Score following endoscopy has previously been recommended to predict mortality. 55152 However the AUROC figures for mortality using these scores are relatively low. ${ }^{39}$ The accuracy of risk scores to identify need for endoscopic therapy or rebleeding is also relatively low. 383943485354

A systematic review of pre-endoscopy risk scores found that GBS was the optimal pre-endoscopy risk score with GBS of zero demonstrating high sensitivity but low specificity for predicting adverse outcomes. ${ }^{40}$ Although GBS of zero has historically been used to identify very low-risk patients suitable for outpatient management, ${ }^{545556}$ recent large multicentre studies have suggested this threshold could be increased to GBS $\leq 1.8394957$ This GBS threshold strategy has been recommended by recent international AUGIB guidelines. ${ }^{46}$ The recently described pre-endoscopic CANUKA Score shows promise in identifying lowrisk patients presenting with UGIB, however only $7 \%$ patients were encompassed by its low-risk threshold, compared with $24 \%$ using the GBS $\leq 1$ threshold..$^{58}$ Further data on this score are awaited.

\section{RX (TREATMENT)}

We recommend intravenous terlipressin is given to all patients with suspected cirrhosis/variceal bleeding. However, caution should be exercised in patients with ischaemic heart disease or peripheral vascular disease Level of evidence: High

Level of recommendation: Strong

Agreement: 100\%
Bundle recommendation: Intravenous terlipressin $2 \mathrm{mg}$ four times a day in case of suspected variceal bleeding (80\% agreement)

Variceal bleeding should be suspected in patients presenting with AUGIB who have known cirrhosis or have clinical parameters that would suggest cirrhosis. The UK variceal bleed guidelines recommend administering terlipressin or somatostatin as soon as variceal bleeding is suspected, ${ }^{59}$ for up to 5 days or until attainment of haemostasis, with octreotide as an alternative. The efficacy of intravenous terlipressin in variceal bleeding has been presented in a Cochrane meta-analysis of 22 RCTs $(n=1609) .{ }^{60}$ Seven studies $(n=443)$ compared terlipressin to placebo, of which five were considered to be high quality. This showed a significant reduction in all-cause mortality compared with placebo (34\% relative risk reduction), improved haemostasis and reduced transfusion requirement. Similar results were found in an updated meta-analysis in 2012. ${ }^{61}$ A more recent multicentre RCT $(n=780)$ reported non-inferiority of terlipressin compared with octreotide and somatostatin, with no difference in outcomes of haemorrhage control, rebleeding and mortality. ${ }^{62}$ The BSG/BASL cirrhosis bundle suggests caution in patients with known ischaemic heart disease or peripheral vascular disease and mandatory ECG assessment in patients aged over 65 years. ${ }^{11}$

We recommend giving intravenous antibiotics to all patients with suspected cirrhosis/variceal bleeding

Level of evidence: High

Strength of recommendation: Strong

Agreement: 100\%

Bundle recommendation: Intravenous antibiotics if suspected cirrhosis/variceal bleeding (100\% agreement)

Bacterial infections are common in patients with cirrhosis and AUGIB and are associated with rebleeding and mortality. ${ }^{63}$ A Cochrane meta-analysis of 12 RCTs $(n=1241)$ concluded that antibiotic prophylaxis in this context was superior to placebo in reducing mortality, bacterial infections, rebleeding and LOS. ${ }^{64}$ The benefit of antibiotic prophylaxis has also been observed following endoscopic haemostasis for peptic ulcer bleeding. ${ }^{6566}$ There is evidence to support the use of intravenous prophylactic antibiotics over oral agents. Fernandez et $a l^{67}$ randomised patients $(n=111)$ with AUGIB and cirrhosis to either oral norfloxacin (400 mg twice daily) or intravenous ceftriaxone $(1 \mathrm{~g} /$ day) for 7 days, and assessed outcomes within 10 days. Patients assigned to intravenous ceftriaxone had lower rates of proven infections, bacteraemia and spontaneous bacterial peritonitis. In accordance with the BSG/BASL cirrhosis bundle, patients with cirrhosis and AUGIB should be empirically managed as variceal bleeding and commenced on antibiotic prophylaxis according to local antimicrobial policy. 
We recommend continuing aspirin at presentation

Level of evidence: Moderate

Level of recommendation: Strong

Agreement: 90\%

Bundle recommendation: Continue aspirin (80\% agreement)

We recommend interrupting P2Y12 inhibitors until haemostasis is achieved unless the patient has coronary artery stents, in which case, a decision should be undertaken after discussion with a cardiologist

Level of evidence: Moderate

Level of recommendation: Strong

Agreement (Round 3): 80\%

Bundle recommendation: Unless the patient has major AUGIB, continue P2Y12 inhibitor in patients with coronary artery stents until discussion with cardiology (60\% agreement-rejected)

We recommend interrupting warfarin therapy at presentation

Level of evidence: Low

Level of recommendation: Strong

Agreement: 80\%

Bundle recommendation: Suspend warfarin (100\% agreement)

We recommend interrupting direct oral anticoagulant (DOAC) therapy at presentation

Level of evidence: Low

Level of recommendation: Strong

Agreement: 90\%

Bundle recommendation: Suspend DOAC (100\% agreement)

\section{ANTITHROMBOTIC THERAPY}

Antithrombotic therapy confers a balance of beneficial antithrombotic effects versus risk of AUGIB. In AUGIB, emergency endoscopy can provide effective haemostasis, and antithrombotic therapy may be temporarily interrupted depending on the indication. ${ }^{68}$

\section{ASPIRIN}

In patients on low-dose aspirin for secondary prevention, aspirin discontinuation is associated with a threefold increased risk of cardiovascular or cerebrovascular events, the majority of which occurred within 7-10 days. ${ }^{69} 70$ An RCT comparing continuation of low-dose $(80 \mathrm{mg})$ aspirin therapy or discontinuation (placebo) following endoscopic haemostasis for peptic ulcer bleeding found increased incidence of recurrent bleeding in the continuation group $(10.3 \%$ vs $5 \%)$ but lower all-cause mortality $(1.3 \%$ vs $12.9 \%) .{ }^{71}$ All patients received intravenous proton pump inhibitor (PPI) therapy. It should be noted that aspirin was discontinued for 8 weeks in the placebo group.

\section{P2Y12 receptor antagonists}

P2Y12 receptor antagonists, for example, clopidogrel, prasugrel and ticagrelor, are commonly co-prescribed with aspirin as DAPT. DAPT is generally recommended for 12 months after deployment of drug-eluting coronary artery stents or 1 month for bare metal stents. There is a high risk of stent thrombosis, with up to a $40 \%$ risk of acute myocardial infarction or death if DAPT therapy is discontinued within this period. ${ }^{72}$ Ideally, DAPT for coronary stents should be continued due to the consequences of stent thrombosis, and it is important to liaise with a cardiologist in the emergency setting. In the event of severe haemorrhage, it may be necessary to temporarily discontinue the P2Y12 inhibitor, but aspirin should be continued, ${ }^{73}$ with the aim to restart the P2Y12 inhibitor within 5 days.$^{74}$ This recommendation is consistent with international guidelines, ${ }^{6875}$ but due to the lack of AUGIBspecific studies and the complexity of the statement, the steering group did not recommend this statement as a stand-alone item in the care bundle.

\section{WARFARIN}

Indications for warfarin can be characterised into low risk or high risk for thrombosis. ${ }^{68}$ Warfarin can be interrupted on presentation with AUGIB, but a plan for resumption should be made. Specific advice on the management of patients in whom reversal of anticoagulation is indicated are outside the scope of this bundle but are available in published guidelines. ${ }^{68}$

\section{DIRECT ORAL ANTICOAGULANTS}

Dabigatran is a thrombin inhibitor, whereas rivaroxaban, apixaban and edoxaban are factor $\mathrm{Xa}$ inhibitors. Unlike warfarin, DOACs have relatively short half-lives, which may be prolonged in renal failure. For minor AUGIB, it is usually sufficient to withhold DOAC therapy and allow the effect to dissipate; severe AUGIB is challenging and advice should be sought from a haematologist. In the case of life-threatening haemorrhage, idarucizumab has been developed as an antidote for dabigatran, ${ }^{76}$ and andexanet for the antifactor Xa inhibitors. ${ }^{77}$

\section{REFER}

We recommend endoscopy is offered to patients admitted with suspected AUGIB within 24 hours of presentation. Patients with ongoing haemodynamic instability will require more urgent endoscopy after resuscitation

Level of evidence: Weak

Level of recommendation: Strong

Agreement: 90\%

Bundle recommendation: Referral to ensure that endoscopy is performed within 24 hours of presentation (100\% agreement)

Endoscopy is the primary diagnostic and therapeutic modality in AUGIB. Time to endoscopy, that is, time from admission/inpatient presentation to endoscopy, is a recognised quality metric in AUGIB.

Two systematic reviews which studied the effect of early endoscopy ( $\leq 24$ hours) found no benefit 
on mortality and the need for surgery but identified a reduction in LOS. ${ }^{78} 79$ Several studies assessed the effect of endoscopy timing on clinical outcome in non-variceal AUGIB, although these differed in study design. One US study identified delayed endoscopy ( $>24$ hours after admission) as an independent predictor of mortality in both variceal bleeding and non-variceal AUGIB. ${ }^{80}$ The role of very early endoscopy ( $<12$ hours) in patients with NVUGIB remains controversial. $^{81} 82$ Endoscopy within 12 hours (vs 12-24hours) has been associated with lower transfusion requirements. ${ }^{81}$ One retrospective analysis assessed timing of endoscopy in low-risk (GBS $\leq 12$ ) versus high-risk $\left(G B S \geq 12\right.$ ) patients. ${ }^{82}$ The timing of endoscopy did not impact on inpatient mortality in low-risk patients, but was significant in the high-risk group, where a threshold of 13 hours was optimal for predicting survival. ${ }^{82}$ No differences were reported for transfusion requirements, rebleeding or need for surgery, which suggests that mortality in these patients may be unrelated to AUGIB. ${ }^{82}$ An RCT from Hong Kong compared $<6$ hours vs $<24$ hours endoscopy in high-risk patients $(\mathrm{GBS} \geq 12){ }^{83}$ with preliminary results reporting no difference in major outcomes.

In contrast, a retrospective study $(n=81)$ found no differences in clinical outcomes (mortality, rebleeding or surgery or LOS) between patients receiving endoscopy within 3 hours vs 48 hours. There was however a higher need for endoscopic therapy in the early endoscopy group $(\mathrm{p}=0.002) .{ }^{84}$

Several studies have associated very early endoscopy $(<12$ hours) with adverse outcomes. A retrospective study $(n=361)$ reported that patients undergoing endoscopy within 12 hours for AUGIB had a fivefold increased risk of incurring the composite outcome of rebleeding, surgical or radiological intervention or need for repeat endoscopic intervention. ${ }^{85}$ Other confounders may exist, but one possible explanation could be inadequate resuscitation, as patients who underwent early endoscopy had significantly lower blood pressure and higher heart rate. A nationwide cohort study of patients with peptic ulcer bleeding from Denmark $(n=12601)$ associated endoscopy undertaken too early, or too late, with higher mortality, particularly in patients with higher levels of comorbidity or haemodynamic instability. ${ }^{86}$ The authors suggested that a period of 6-12 hours prior to endoscopy may allow time for resuscitation and medical optimisation.

Most guidelines recommend endoscopy for all patients within 24 hours, and for patients with haemodynamic instability to undergo more urgent endoscopy. ${ }^{5} 687$ ESGE guidelines also recommend very early endoscopy in those with contraindications to the interruption of anticoagulation, although data were limited. ${ }^{6}$ For suspected acute variceal bleeding, the European and American guidelines suggest endoscopy with 12 hours. ${ }^{88}{ }^{89}$ However, the 2015 UK variceal bleeding guidance proposes endoscopy within
24 hours for all, except for unstable patients who should have endoscopy immediately after resuscitation, ${ }^{59}$ as changing the timing of endoscopy to within 12 hours has not been shown to be associated with a survival benefit. ${ }^{90}$

Based on the available evidence and international guidelines, we recommend that all patients with AUGIB undergo endoscopy within 24 hours of admission, with earlier endoscopy for those with ongoing haemodynamic instability. The endoscopy referral or request should be made in a timely manner in order to achieve this outcome. ${ }^{91}$

\section{REVIEW}

We suggest that the endoscopy report should be reviewed by the ward team

Level of evidence: Very low

Level of recommendation: Strong

Agreement: 90\%

Bundle recommendation: Review endoscopy report (100\% agreement)

The endoscopy report provides an overview of each procedure. For AUGIB, this should include endoscopic findings and haemorrhagic stigmata, therapies administered, certainty of haemostasis, complications, further management and rebleeding plan. ${ }^{792}$ One Canadian prospective study studied the impact of a checklist on the endoscopy report in patients with non-variceal AUGIB, ${ }^{93}$ which included instructions on diet, drugs and discharge. Checklist compliance led to reductions in LOS. Although the impact of a rebleeding plan has not been specifically studied, this featured in the NCEPOD recommendations as a pragmatic and clinically relevant standard of care. ${ }^{7}$ On their return to the ward following endoscopy, the patient and endoscopy report should be reviewed by the receiving ward team and management recommendations instigated.

\section{We suggest that all patients with varices or those requiring endoscopic therapy are referred to a gastroenterology service}

Level of evidence: Low

Level of recommendation: Strong

Agreement: 90\%

Bundle recommendation: Refer to GI specialist if requiring therapeutic endoscopy (100\% agreement)

Several studies have assessed the role of specialist care for AUGIB under gastroenterology teams. A singlecentre prospective UK study by Sanders et al assessed the outcomes of 900 consecutive patients with AUGIB admitted to a dedicated GI bleeding unit. ${ }^{94}$ All patients received protocolised care by dedicated gastroenterologists and nurses, and had access to 24 hours endoscopy and interventional radiology. Compared with data from the 1995 UK audit of AUGIB, mortality adjusted by PER and post-endoscopy Rockall Scores were significantly lower in the specialist unit. This study echoed the findings of a previous retrospective UK-based study 
without propensity matching. ${ }^{95}$ A retrospective Italian multicentre analysis $(n=13427)$ reported that specialist gastroenterology care was associated with reduced 30 -day mortality (OR $0.55,95 \%$ CI 0.37 to 0.82 ), which remained significant after propensity adjustment and in patients receiving endoscopy. ${ }^{96}$

Based on the study by Sanders et al, the Scottish Intercollegiate Guidelines Network recommended that patients with AUGIB should be admitted, assessed and managed in a dedicated gastrointestinal bleeding unit. ${ }^{87}$ We recommend that patients with endoscopically confirmed AUGIB, particularly those requiring therapeutic haemostasis, should be referred to a specialist service for ongoing input. Patients with evidence of varices are at risk of decompensation from underlying cirrhosis, and should also be referred for specialist care and follow-up.

\section{We recommend patients with bleeding from ulcers} with high-risk stigmata at endoscopy receive high dose intravenous proton pump inhibitor (PPI) therapy; highdose oral PPIs may be considered as an alternative

Level of evidence: High

Level of recommendation: Strong

Agreement: 90\%

Bundle recommendation: PPI if high risk ulcer postendoscopy (100\% agreement)

The role of PPI infusion in patients with high-risk, non-variceal AUGIB is supported by meta-analysis data. ${ }^{97} 98$ The NICE guidelines recommend offering PPI to patients with non-variceal AUGIB with endoscopic stigmata of recent haemorrhage, ${ }^{5}$ whereas ESGE recommends intravenous PPI for patients requiring endoscopic haemostasis or ulcers with adherent clot. ${ }^{6}$ Although PPI infusion ( $80 \mathrm{mg}$ bolus followed by $8 \mathrm{mg} /$ hour for 72 hours) was recommended, intermittent intravenous PPI and oral high-dose PPI could be considered as alternatives. ${ }^{46}$

A meta-analysis of 13 RCTs comparing various regimens of intermittent intravenous PPI with PPI infusion following endotherapy for high-risk bleeding peptic ulcers reported non-inferiority with intermittent PPI therapy for the outcomes of rebleeding, mortality, urgent interventions, LOS or transfusion requirements. ${ }^{99}$ The authors concluded that intermittent bolus regimens could be used as an alternative to infusion therapy.

RCT and meta-analysis data have failed to demonstrate superiority of PPI therapy based on dosage or route of PPI administration as an adjunct to endoscopic therapy for peptic ulcer disease. ${ }^{100-102}$ The Asia-Pacific guidelines suggest that, as an adjunct to endoscopic treatment, high-dose oral PPI can be used to prevent rebleeding. ${ }^{4}$

We recommend patients with AUGIB in whom antithrombotic therapy is interrupted have a clear plan for resumption

Level of evidence: Low
Level of recommendation: Strong

Agreement: 100\%

Bundle recommendation: Posthaemostasis antithrombotic plan (100\% agreement)

Antithrombotic therapy is often stopped following AUGIB and a clear plan for resumption not made on discharge. Antithrombotic resumption is associated with improved survival and reduced incidence of thrombotic complications. ${ }^{103}$ Thus, all patients in whom antithrombotic therapy has been interrupted should have a clear plan for resumption.

Detailed discussion on the timing of antithrombotic resumption is beyond the scope of this bundle but is available from international guidelines. ${ }^{4} 6875$ Inclusion of a statement on resumption of antithrombotics was unanimously supported by the working group.

\section{DISCUSSION}

Despite the availability of multiple high-quality international guidelines, recent evidence confirms persisting poor performance in managing patients with AUGIB. ${ }^{791}$ The BSG EQIP has identified a clinical need to improve the quality of endoscopy and service provision in AUGIB. Previous interventions in the UK, for example in colonoscopy training and certification, provided by the Joint Advisory Group on Gastrointestinal Endoscopy, have been shown to significantly improve performance and outcomes in clinical practice. ${ }^{104}$ In addition, other care bundles such as the BSG/BASL cirrhosis bundle have led to improvements in patient-centred outcomes. ${ }^{12}$

Many of the areas for possible improvement in AUGIB management are in the pre-endoscopy and post-endoscopy care of patients either admitted with AUGIB to hospital or who develop bleeding while hospitalised with another condition. We have therefore convened a multidisciplinary, multisociety development group to construct a care bundle targeted at non-specialist staff in emergency departments, acute medical or surgical wards aiming to improve management in the first 24 hours of care.

In developing this bundle, we have focused on six domains with 14 bundle items. The care bundle comprises a series of evidence-based measures which are associated with improved outcomes compared with if they were not performed. In addition, preliminary evidence has reported improved outcomes when using the bundle. ${ }^{105}$ The brevity and choice of items make this a simple and quick tool to enhance utilisation in busy clinical practice. We believe that, if implemented, the AUGIB bundle could ensure standardised, evidencebased care of the highest quality in hospitals in the UK and in other international healthcare environments.

\section{Author affiliations}

${ }^{1} J o i n t$ Advisory Group on Gastrointestinal Endoscopy, Royal College of Physicians, London, UK

${ }^{2}$ Medical and Dental Sciences, University of Birmingham, Birmingham, UK

${ }^{3}$ Endoscopy Unit, Dudley Group NHS Foundation Trust, Dudley, UK 
${ }^{4}$ Department of Gastroenterology, Newcastle Upon Tyne Hospitals NHS Foundation Trust, Newcastle Upon Tyne, UK

${ }^{5}$ Department of Gastroenterology, Glasgow Royal Infirmary, Glasgow, UK ${ }^{6} \mathrm{NHS}$ Blood and Transplant, Oxford, UK

${ }^{7}$ Association of Upper Gastrointestinal Surgeons of Great Britain and Ireland, London, UK

${ }^{8}$ Upper GI Surgery, Royal Gwent Hospital, Newport, UK

${ }^{9}$ Society for Acute Medicine, London, UK

${ }^{10}$ Intensive Care Unit, Royal Berkshire NHS Foundation Trust, Reading, UK

${ }^{11}$ Endoscopy Unit, Sheffield Teaching Hospitals NHS Foundation Trust, Sheffield, UK

${ }^{12}$ Department of Gastroenterology, Royal Wolverhampton Hospitals NHS Trust, Wolverhampton, UK

${ }^{13}$ School of Health Sciences, Birmingham City University, Birmingham, UK

${ }^{14}$ Endoscopy Quality Improvement Programme (EQIP), British Society of

Gastroenterology, London, UK

Twitter KeithSiau@drkeithsiau

Contributors Guarantor of the article: AJM. Conception: KS, SI, AJM. Delphi methodology: KS, AJM. Literature search, evidence synthesis and consensus voting: KS, SH, AJS, LE, AR, AW, MT, MD, AMV, SI, AJM. Patient representative: RD. Manuscript write-up: All authors. All authors approved the final version of the manuscript.

Funding Funded by the British Society of Gastroenterology

Competing interests None declared.

Patient consent for publication Not required.

Provenance and peer review Not commissioned; externally peer reviewed.

Data availability statement All data relevant to the study are included in the article or uploaded as supplementary information

Open access This is an open access article distributed in accordance with the Creative Commons Attribution Non Commercial (CC BY-NC 4.0) license, which permits others to distribute, remix, adapt, build upon this work noncommercially, and license their derivative works on different terms, provided the original work is properly cited, appropriate credit is given, any changes made indicated, and the use is noncommercial. See: http://creativecommons.org/licenses/by-nc/4. $0 /$.

ORCID iD

Keith Siau http://orcid.org/0000-0002-1273-9561

\section{REFERENCES}

1 Button LA, Roberts SE, Evans PA, et al. Hospitalized incidence and case fatality for upper gastrointestinal bleeding from 1999 to 2007: a record linkage study. Aliment Pharmacol Ther 2011;33:64-76.

2 Hearnshaw SA, Logan RFA, Lowe D, et al. Use of endoscopy for management of acute upper gastrointestinal bleeding in the UK: results of a nationwide audit. Gut 2010;59:1022-9.

3 Rockall TA, Logan RF, Devlin HB, et al. Incidence of and mortality from acute upper gastrointestinal haemorrhage in the United Kingdom. Steering Committee and members of the National audit of acute upper gastrointestinal haemorrhage. Bmi 1995;311:222-6.

4 Sung JJY, Chiu PWY, Chan FKL, et al. Asia-Pacific Working group consensus on non-variceal upper gastrointestinal bleeding: an update 2018. Gut 2018;67:1757-68.

5 NICE. Acute upper gastrointestinal bleeding in over 16S: management, 2012. Available: https://www.nice.org.uk/ guidance/cg141 [Accessed cited 20th Feb 2018].

6 Gralnek I, Dumonceau J-M, Kuipers E, et al. Diagnosis and management of nonvariceal upper gastrointestinal hemorrhage: European Society of gastrointestinal endoscopy (ESGE) guideline. Endoscopy 2015;47:a1-46.

7 NCEPOD. Time to get control? A review of the care received by patients who had a severe gastrointestinal haemorrhage,
2015. Available: http://www.ncepod.org.uk/2015report1/ downloads/TimeToGetControlFullReport.pdf

8 Robb E, Jarman B, Suntharalingam G, et al. Using care bundles to reduce in-hospital mortality: quantitative survey 2010;340:c1234.

9 Horner DL, Bellamy MC. Care bundles in intensive care. Continuing Edu Anaesthesia Critical Care Pain 2012;12:199_ 202.

10 Daniels R, Nutbeam T, McNamara G, et al. The sepsis six and the severe sepsis resuscitation bundle: a prospective observational cohort study. Emerg Med J 2011;28:507-12.

11 McPherson S, Dyson J, Austin A, et al. Response to the NCEPOD report: development of a care bundle for patients admitted with decompensated cirrhosis-the first $24 \mathrm{~h}$. Frontline Gastroenterol 2016;7:16-23.

12 Dyson JK, Rajasekhar P, Wetten A, et al. Implementation of a 'care bundle' improves the management of patients admitted to hospital with decompensated cirrhosis. Aliment Pharmacol Ther 2016;44:1030-8.

13 Rajasekhar P, Rees C, Bramble M, et al. A multicenter pragmatic study of an evidence-based intervention to improve adenoma detection: the quality improvement in colonoscopy (QIC) study. Endoscopy 2015;47:217-24.

14 Lavallée JF, Gray TA, Dumville J, et al. The effects of care bundles on patient outcomes: a systematic review and metaanalysis. Implementation Science 2017;12:142.

15 Rees CJ, Koo S, Anderson J, et al. British Society of gastroenterology endoscopy quality improvement programme (EQIP): overview and progress. Frontline Gastroenterol 2019;10:148-53.

16 Guyatt GH, Oxman AD, Vist GE, et al. Grade: an emerging consensus on rating quality of evidence and strength of recommendations. BMJ 2008;336:924-6.

17 Laine L, Laursen SB, Zakko L, et al. Severity and outcomes of upper gastrointestinal bleeding with bloody vs. coffeegrounds hematemesis. Am J Gastroenterol 2018;113:35866.

18 Bozkurt S, Köse A, Arslan ED, et al. Validity of modified early warning, Glasgow Blatchford, and pre-endoscopic Rockall scores in predicting prognosis of patients presenting to emergency department with upper gastrointestinal bleeding. Scand J Trauma Resusc Emerg Med 2015;23:109.

19 McGinley A, Pearse RM. A national early warning score for acutely ill patients. BMJ 2012;345:e5310.

20 Lu B, Li M-Q, Li J-Q. The use of limited fluid resuscitation and blood Pressure-Controlling drugs in the treatment of acute upper gastrointestinal hemorrhage concomitant with hemorrhagic shock. Cell Biochem Biophys 2015;72:461-3.

21 Baradarian R, Ramdhaney S, Chapalamadugu R, et al. Early intensive resuscitation of patients with upper gastrointestinal bleeding decreases mortality. Am J Gastroenterol 2004;99:619-22.

22 NICE. Intravenous fluid therapy in adults in hospital, 2013. Available: https://www.nice.org.uk/guidance/cg174 [Accessed 1st Jul 2018].

23 Roberts I, Alderson P, Bunn F, et al. Colloids versus crystalloids for fluid resuscitation in critically ill patients. Cochrane Database Syst Rev 2004 (Published Online First: 2004/10/21).

24 Myburgh JA, Finfer S, Bellomo R, et al. Hydroxyethyl starch or saline for fluid resuscitation in intensive care. N Engl J Med 2012;367:1901-11.

25 Blair SD, Janvrin SB, McCollum CN, et al. Effect of early blood transfusion on gastrointestinal haemorrhage. Br J Surg 1986;73:783-5.

26 Jairath V, Kahan BC, Gray A, et al. Restrictive versus liberal blood transfusion for acute upper gastrointestinal bleeding (trigger): a pragmatic, open-label, cluster randomised feasibility trial. The Lancet 2015;386:137-44. 
27 Villanueva C, Colomo A, Bosch A, et al. Transfusion strategies for acute upper gastrointestinal bleeding. N Engl J Med 2013;368:11-21.

28 Villarejo F, Rizzolo M, Lopez E, et al. Acute anemia in high digestive hemorrhage. Margins of security for their handling without transfusion of red globules]. Acta Gastroenterol Latinoam 1999;29:261-70.

29 Lee JM, Chun HJ, Lee JS, et al. Sa1888 target level for hemoglobin correction in patients with acute nonvariceal upper gastrointestinal bleeding. Gastroenterology 2014;146:S-321.

30 Odutayo A, Desborough MJR, Trivella M, et al. Restrictive versus liberal blood transfusion for gastrointestinal bleeding: a systematic review and meta-analysis of randomised controlled trials. Lancet Gastroenterol Hepatol 2017;2:354-60.

31 Kass LE, Tien IY, Ushkow BS, et al. Prospective crossover study of the effect of phlebotomy and intravenous crystalloid on hematocrit. Acad Emerg Med 1997;4:198-201.

32 Hunt BJ, Allard S, Keeling D, et al. A practical guideline for the haematological management of major haemorrhage. $\mathrm{Br} J$ Haematol 2015;170:788-803.

33 Hampers MJ, Surgenor SD, Spanjian K, et al. Icu care for patients with gastrointestinal bleeding: impact on cost and outcome. Clinical Intensive Care 2002;13:109-13.

34 Thomas D, Wee M, Clyburn P, et al. Blood transfusion and the anaesthetist: management of massive haemorrhage. Anaesthesia 2010;65:1153-61.

35 Estcourt LJ, Birchall J, Allard S, et al. Guidelines for the use of platelet transfusions. Br J Haematol 2017;176:365-94.

36 Estcourt LJ, Curry NS, Simons GN, et al. Platelet transfusion for the actively bleeding patient. In: Sweeney J, Lozano M, eds. Platelet transfusion therapy, 2013: 271-320.

37 NICE. Blood transfusion NG24, 2015. Available: https:// www.nice.org.uk/guidance/ng24

38 Laursen SB, Dalton HR, Murray IA, et al. Performance of new thresholds of the Glasgow Blatchford score in managing patients with upper gastrointestinal bleeding. Clin Gastroenterol Hepatol 2015;13:115-21.

39 Stanley AJ, Laine L, Dalton HR, et al. Comparison of risk scoring systems for patients presenting with upper gastrointestinal bleeding: international multicentre prospective study. BMJ 2017;356:i6432.

40 Ramaekers R, Mukarram M, Smith CAM, et al. The predictive value of Preendoscopic risk scores to predict adverse outcomes in emergency department patients with upper gastrointestinal bleeding: a systematic review. Acad Emerg Med 2016;23:1218-27.

41 Robertson M, Majumdar A, Boyapati R, et al. Risk stratification in acute upper Gi bleeding: comparison of the AIMS65 score with the Glasgow-Blatchford and Rockall scoring systems. Gastrointest Endosc 2016;83:1151-60.

42 Budimir I, Stojsavljević S, Baršić N, et al. Scoring systems for peptic ulcer bleeding: which one to use? WJG 2017;23:74508.

43 Martínez-Cara JG, Jiménez-Rosales R, Úbeda-Muñoz $\mathrm{M}$, et al. Comparison of AIMS65, Glasgow-Blatchford score, and Rockall score in a European series of patients with upper gastrointestinal bleeding: performance when predicting in-hospital and delayed mortality. United European Gastroenterol J 2016;4:371-9.

44 Abougergi MS, Charpentier JP, Bethea E, et al. A prospective, multicenter study of the AIMS65 score compared with the Glasgow-Blatchford score in predicting upper gastrointestinal hemorrhage outcomes. J Clin Gastroenterol 2016;50:464-9.

45 Yaka E, Yılmaz S, Doğan Nurettin Özgür, et al. Comparison of the Glasgow-Blatchford and AIMS65 scoring systems for risk stratification in upper gastrointestinal bleeding in the emergency department. Acad Emerg Med 2015;22:22-30.
46 Park SM, Yeum SC, Kim B-W, et al. Comparison of AIMS65 score and other scoring systems for predicting clinical outcomes in Koreans with Nonvariceal upper gastrointestinal bleeding. Gut Liver 2016;10:526-31.

47 Yang HM, Jeon SW, Jung JT, et al. Comparison of scoring systems for nonvariceal upper gastrointestinal bleeding: a multicenter prospective cohort study. J Gastroenterol Hepatol 2016;31:119-25.

48 Pang SH, Ching JYL, Lau JYW, et al. Comparing the Blatchford and pre-endoscopic Rockall score in predicting the need for endoscopic therapy in patients with upper $\mathrm{Gi}$ hemorrhage. Gastrointest Endosc 2010;71:1134-40.

49 Le Jeune IR, Gordon AL, Farrugia D, et al. Safe discharge of patients with low-risk upper gastrointestinal bleeding (UGIB): can the use of Glasgow-Blatchford bleeding score be extended? Acute Med 2011;10:176-81.

50 Hyett BH, Abougergi MS, Charpentier JP, et al. The AIMS65 score compared with the Glasgow-Blatchford score in predicting outcomes in upper Gi bleeding. Gastrointest Endosc 2013;77:551-7.

51 Rockall TA, Logan RF, Devlin HB, et al. Risk assessment after acute upper gastrointestinal haemorrhage. Gut 1996;38:31621.

52 Gralnek IM, Dulai GS. Incremental value of upper endoscopy for triage of patients with acute non-variceal upper-GI hemorrhage. Gastrointest Endosc 2004;60:9-14.

53 Stanley AJ, Dalton HR, Blatchford O, et al. Multicentre comparison of the Glasgow Blatchford and Rockall scores in the prediction of clinical end-points after upper gastrointestinal haemorrhage. Aliment Pharmacol Ther 2011;34:470-5.

54 Bryant RV, Kuo P, Williamson K, et al. Performance of the Glasgow-Blatchford score in predicting clinical outcomes and intervention in hospitalized patients with upper Gi bleeding. Gastrointest Endosc 2013;78:576-83.

55 Chen I-C, Hung M-S, Chiu T-F, et al. Risk scoring systems to predict need for clinical intervention for patients with nonvariceal upper gastrointestinal tract bleeding. Am J Emerg Med 2007;25:774-9.

56 Stanley AJ, Ashley D, Dalton HR, et al. Outpatient management of patients with low-risk upper-gastrointestinal haemorrhage: multicentre validation and prospective evaluation. The Lancet 2009;373:42-7.

57 Srirajaskanthan R, Conn R, Bulwer C, et al. The Glasgow Blatchford scoring system enables accurate risk stratification of patients with upper gastrointestinal haemorrhage. Int J Clin Pract 2010;64:868-74.

58 Oakland K, Kahan BC, Guizzetti L, et al. Development, validation, and comparative assessment of an international scoring system to determine risk of upper gastrointestinal bleeding. Clin Gastroenterol Hepatol 2019;17:1121-9.

59 Tripathi D, Stanley AJ, Hayes PC, et al. Uk guidelines on the management of variceal haemorrhage in cirrhotic patients. Gut 2015;64:1680-704.

60 Ioannou GN, Doust J, Rockey DC, et al. Terlipressin for acute esophageal variceal hemorrhage. Cochrane Database Syst Rev 2003;24.

61 Wells M, Chande N, Adams P, et al. Meta-Analysis: vasoactive medications for the management of acute variceal bleeds. Aliment Pharmacol Ther 2012;35:1267-78.

62 Seo YS, Park SY, Kim MY, et al. Lack of difference among terlipressin, somatostatin, and octreotide in the control of acute gastroesophageal variceal hemorrhage. Hepatology 2014;60:954-63.

63 Bernard B, Cadranel J-F, Valla D, et al. Prognostic significance of bacterial infection in bleeding cirrhotic patients: a prospective study. Gastroenterology 1995;108:1828-34.

64 Chavez-Tapia NC, Barrientos-Gutierrez T, Tellez-Avila F, et al. Meta-analysis: antibiotic prophylaxis for cirrhotic patients 
with upper gastrointestinal bleeding - an updated Cochrane review. Aliment Pharmacol Ther 2011;34:509-18.

65 Kuo M-T, Yang S-C, Lu L-S, et al. Predicting risk factors for rebleeding, infections, mortality following peptic ulcer bleeding in patients with cirrhosis and the impact of antibiotics prophylaxis at different clinical stages of the disease. BMC Gastroenterol 2015;15:61.

66 Yang S-C, Chen J-C, Tai W-C, et al. The influential roles of antibiotics prophylaxis in cirrhotic patients with peptic ulcer bleeding after initial endoscopic treatments. PLoS One 2014;9:e96394-e94.

67 Fernández J, Ruiz del Arbol L, Gómez C, et al. Norfloxacin vs ceftriaxone in the prophylaxis of infections in patients with advanced cirrhosis and hemorrhage. Gastroenterology 2006;131:1049-56.

68 Veitch AM, Vanbiervliet G, Gershlick AH, et al. Endoscopy in patients on antiplatelet or anticoagulant therapy, including direct oral anticoagulants: British Society of gastroenterology (Bsg) and European Society of gastrointestinal endoscopy (ESGE) guidelines. Gut 2016;65:374-89.

69 Biondi-Zoccai GGL, Lotrionte M, Agostoni P, et al. A systematic review and meta-analysis on the hazards of discontinuing or not adhering to aspirin among 50279 patients at risk for coronary artery disease. Eur Heart $J$ 2006;27:2667-74.

70 Maulaz AB, Bezerra DC, Michel P, et al. Effect of discontinuing aspirin therapy on the risk of brain ischemic stroke. Arch Neurol 2005;62:1217-20.

71 Sung JJYet al. Continuation of low-dose aspirin therapy in peptic ulcer bleeding. Ann Intern Med 2010;152:1-9.

72 Iakovou Iet al. Incidence, predictors, and outcome of thrombosis after successful implantation of drug-eluting stents. JAMA 2005;293:2126-30.

73 Halvorsen S, Storey RF, Rocca B, et al. Management of antithrombotic therapy after bleeding in patients with coronary artery disease and/or atrial fibrillation: expert consensus paper of the European Society of cardiology Working group on thrombosis. Eur Heart J 2016;46:ehw45462.

74 Eisenberg MJ, Richard PR, Libersan D, et al. Safety of shortterm discontinuation of antiplatelet therapy in patients with drug-eluting stents. Circulation 2009;119:1634-42.

75 Chan FKL, Goh K-L, Reddy N, et al. Management of patients on antithrombotic agents undergoing emergency and elective endoscopy: joint Asian Pacific association of gastroenterology (APAGE) and Asian Pacific Society for digestive endoscopy (APSDE) practice guidelines. Gut 2018;67:405-17.

76 Pollack CV, Reilly PA, Eikelboom J, et al. Idarucizumab for dabigatran reversal. N Engl J Med 2015;373:511-20.

77 Connolly SJ, Crowther M, Eikelboom JW, et al. Full study report of Andexanet alfa for bleeding associated with factor Xa inhibitors. N Engl J Med 2019.

78 Lanas A, Aabakken L, Fonseca J, et al. Variability in the management of nonvariceal upper gastrointestinal bleeding in Europe: an observational study. Adv Ther 2012;29:1026-36.

79 Spiegel BMR, Vakil NB, Ofman JJ. Endoscopy for acute Nonvariceal upper gastrointestinal tract hemorrhage: is Sooner better? Arch Intern Med 2001;161:1393-404.

80 Wysocki JD, Srivastav S, Winstead NS. A nationwide analysis of risk factors for mortality and time to endoscopy in upper gastrointestinal haemorrhage. Aliment Pharmacol Ther 2012;36:30-6.

81 Lin HJ, Wang K, Perng CL, et al. Early or delayed endoscopy for patients with peptic ulcer bleeding. A prospective randomized study. J Clin Gastroenterol 1996;22:267-71.

82 Lim L, Ho K, Chan Y, et al. Urgent endoscopy is associated with lower mortality in high-risk but not low-risk nonvariceal upper gastrointestinal bleeding. Endoscopy 2011;43:300-6.
83 Wong JC, Lau JY, Tang RS, et al. 785 urgent versus early endoscopy for upper gastrointestinal bleeding with GlasgowBlatchford score $\geq 12$. Gastroenterology 2015;148:S-154.

84 Schacher GM, Lesbros-Pantoflickova D, Ortner MA, et al. Is Early Endoscopy in the Emergency Room Beneficial in Patients with Bleeding Peptic Ulcer? A "Fortuitously Controlled" Study. Endoscopy 2005;37:324-8.

85 Kumar NL, Cohen AJ, Nayor J, et al. Timing of upper endoscopy influences outcomes in patients with acute nonvariceal upper Gi bleeding. Gastrointest Endosc 2017;85:945-52.

86 Laursen SB, Leontiadis GI, Stanley AJ, et al. Relationship between timing of endoscopy and mortality in patients with peptic ulcer bleeding: a nationwide cohort study. Gastrointest Endosc 2017;85:936-44.

87 SIGN. Management of acute upper and lower gastrointestinal bleeding, 2008. Available: http://www.sign.ac.uk/assets/ sign105.pdf [Accessed 20 June 2018].

88 de Franchis R. Expanding consensus in portal hypertension: report of the Baveno VI consensus workshop: Stratifying risk and individualizing care for portal hypertension. J Hepatol 2015;63:743-52.

89 Garcia-Tsao G, Abraldes JG, Berzigotti A, et al. Portal hypertensive bleeding in cirrhosis: risk stratification, diagnosis, and management: 2016 practice guidance by the American association for the study of liver diseases. Hepatology 2017;65:310-35.

90 Cheung J, Soo I, Bastiampillai R, et al. Urgent vs. nonurgent endoscopy in stable acute variceal bleeding. Am J Gastroenterol 2009;104:1125-9.

91 Siau K, Hodson J, Ingram R, et al. Time to endoscopy for acute upper gastrointestinal bleeding: results from a prospective multicentre trainee-led audit. United European Gastroenterol J 2019;7:199-209.

92 Bretthauer M, Aabakken L, Dekker E, et al. Requirements and standards facilitating quality improvement for reporting systems in gastrointestinal endoscopy: European Society of gastrointestinal endoscopy (ESGE) position statement. Endoscopy 2016;48:291-4.

93 Romagnuolo J, Flemons WW, Perkins L, et al. Postendoscopy checklist reduces length of stay for non-variceal upper gastrointestinal bleeding. Int J Qual Health Care 2005;17:249-54

94 Sanders DS, Perry MJ, Jones SG, et al. Effectiveness of an upper-gastrointestinal haemorrhage unit: a prospective analysis of 900 consecutive cases using the Rockall score as a method of risk standardisation. Eur J Gastroenterol Hepatol 2004;16:487-94

95 Sanderson JD, Taylor RF, Pugh S, et al. Specialized gastrointestinal units for the management of upper gastrointestinal haemorrhage. Postgrad Med J 1990;66:6546.

96 Kohn A, Ancona C, Belleudi V, et al. The impact of endoscopy and specialist care on 30-day mortality among patients with acute non-variceal upper gastrointestinal hemorrhage: an Italian population-based study. Dig Liver Dis 2010;42:629-34.

97 Leontiadis GI, Sharma VK, Howden CW. Systematic review and meta-analysis of proton pump inhibitor therapy in peptic ulcer bleeding. BMJ 2005;330:568.

98 Scally B, Emberson JR, Spata E, et al. Effects of gastroprotectant drugs for the prevention and treatment of peptic ulcer disease and its complications: a meta-analysis of randomised trials. Lancet Gastroenterol Hepatol 2018;3:23141

99 Sachar H, Vaidya K, Laine L. Intermittent vs continuous proton pump inhibitor therapy for high-risk bleeding ulcers: a systematic review and meta-analysis. JAMA Intern Med 2014;174:1755-62. 
100 Sung JJY, Suen B-Y, Wu JCY, et al. Effects of intravenous and oral esomeprazole in the prevention of recurrent bleeding from peptic ulcers after endoscopic therapy. Am J Gastroenterol 2014;109:1005-10.

101 Neumann I, Letelier LM, Rada G, et al. Comparison of different regimens of proton pump inhibitors for acute peptic ulcer bleeding. Cochrane Database Syst Rev 2013;103.

102 Tringali A, Manta R, Sica M, et al. Comparing intravenous and oral proton pump inhibitor therapy for bleeding peptic ulcers following endoscopic management: a systematic review and meta-analysis. Br J Clin Pharmacol 2017;83:1619-35.
103 Siau K, Hannah JL, Hodson J, et al. Stopping antithrombotic therapy after acute upper gastrointestinal bleeding is associated with reduced survival. Postgrad Med J 2018;94:137-42.

104 Siau K, Green JT, Hawkes ND, et al. Impact of the joint Advisory group on gastrointestinal endoscopy (JAG) on endoscopy services in the UK and beyond. Frontline Gastroenterol 2019;10:93-106.

105 Donnelly MC, Saffouri E, Pugmire J, et al. PTH012 Implementation of UK acute upper GI bleeding bundle results in significant improvements in quality standards. Gut 2019;68:A19. 